\title{
EDUCATIONAL SOFTWARE TO LEARN THE ESSENTIALS OF ENGINEERING GRAPHICS
}

\begin{abstract}
This paper presents a novel educational software package which develops an Interactive Didactic Application (IDA) generated in the Polytechnic University of Catalonia (UPC), and which contains the essentials of Engineering Graphics according to ISO norms. It is an interactive multimedia application which adapts easily to all engineering studies, according to the needs of each course, and which is the nucleus of Computer Assisted Teaching (CAT).
\end{abstract}

Keywords: Educational Software, Engineering Graphics, Technical Drawing, Interactive Didactic Application (IDA), Computer Supported Instruction (CSI).

\section{INTRODUCTION. OBJECTIVES}

The search for improvement in teaching methods has led to the incorporation of dynamic elements in teaching materials. These materials are very efficient when dealing with mechanisms of non uniform complex geometry, and which have a restricting influence on other mechanisms, which in turn restrict the degree of freedom of the first mechanisms. In these cases it is necessary to use concepts such as direct kinematics, inverse kinematics, links, hierarchies and inheritances. Three-dimensional models with views from all necessary points are required.

The Interactive Didactic Application (IDA) developed meets the proposed objectives and improves the quality of the teaching and learning process [1]. The generation of this ADI has used multimedia techniques with the teaching objective to explain the concepts relating to analysis, functioning, standardized representation and simulation of movement.

The importance of engineering graphics and the use of educational software in teaching has been shown in many articles [2-4]. 
The teaching objectives are the following:

1) Bring reality closer to the student.

2) Stimulate interest in engineering.

3) Make the learning process easier.

4) Increase the possibilities of showing examples to respond to students' queries.

5) Extend understanding of mechanisms and their related concepts, view tables and graphics.

6) Facilitate the representation of complex situations using moving images (virtual mechanisms, laboratory simulations).

7) Stimulate scientific curiosity, inventiveness, imagination and creativity.

8) Improve greatly the understanding of concepts and explanations, develop the capacity for spatial vision, as well as academic performance.

9) The system helps the teacher to repeat concepts and provides a complement to presentations.

Navigation within the application allows the user to reach any concept and its related actions interactively, many of which are animations which make understanding of the concept easier. This allows the student to work progressively and repeat processes as many times as necessary.

The software chosen is Authorware by Macromedia [5], which is in widespread use. This type of software allows the development of multimedia systems, providing a working environment which allows programming based on icons, objects and option menus. This language has the possibility of being packaged in WEB format, which helps the creation of multimedia applications for e-learning. They are therefore dynamic and interactive applications which are accessible and compatible with standards, integrating graphics, sound, animation, text and video.

Various programs have been used to create three-dimensional animations, objects and pre-animation drawings, to design objects with appearance, texture, illumination and shading, and assign frames or a spreadsheet with graphics, as well as alteration of digital images, design of presentations, video editing and text processing.

The bulk of the visible multimedia content (text, graphics and animations), as well as some of the non 
visible content (voice or music), can be generated with external applications, thereby taking full advantage of these applications. For example 3D scenes can be incorporated into animations, so many additional resources are possible, such as the opacity of objects which at times must be transparent, the exact illumination to highlight certain concepts or objects are the use of bright colors to highlight elements of the screen at a given moment in a sequence.

The most complex part of the programming is in text, in a format similar to $\mathrm{C}++$, but libraries of other applications can be used for specific tasks possible in Authorware.

\section{SOFTWARE REVISION}

To perform the software revision, we searched for applications developed in this field. Much has been written about the development of multimedia applications relating to different aspects of Technical Drawing [6-9], and the vast majority have been written by teachers in different universities, with a clear didactic focus.

Among the most developed applications, we have found some with a general aims in the environment of research groups [10-14] and others with a specific purpose, with an application in a specific field of engineering $[15,16]$. However, we have not found any application which deals with all the essentials of Engineering Graphics. Therefore this application is truly unique owing to the extent of the content presented, and is also completely innovative.

It should be noted that at each stage of the processes developed by the application there is detailed research, the aim of which is to analyse the most efficient sequence to transmit the concept and carry out the different actions which integrate the resulting steps into the application.

\section{METHODOLOGY}

Each chapter corresponds to its teaching unit; this means there is a large file of texts and a set of image files, which are linked in the general guide to the IDA, in order to coordinate the efforts of the members of the team which has developed this educational software: the director, the authors of its content, the 
designers of geometric models, the designers of static and animated images, the members of the video post-production team, programmers, analysts and the final production team.

In order to begin the project it was necessary first to define the area of interest, the objectives, the content, provide the necessary infrastructure, raise the necessary resource, acquire the equipment and program licenses, adapt the equipment and the software, give training in CAD programs, animation, illustration video and programming, etc., create a concept map, draw up pre-diagrams, guides, interactions, hyperlinks and programming algorithms, model sets and parts geometrically, generate static images, animate sets and scenes, program the appropriate interface for the different media, create typical actions, incorporate the media associated with each action, submit to expert testing and receive feedback on improvements and faults, incorporate the suggested improvements, and finally compile and close the application.

It is important not to neglect the design of the user graphic interface as an important means of achieving a product which fulfils the aim of communication. Our design combines both formal and functional aspects. In terms of formal aspects we have considered space, dividing the screen into areas which usually have the same type of elements, texts, images, etc. We have also considered the presentation of text, choosing the most appropriate fonts, creating a hierarchy using font size and assuring readability, maintaining uniform graphic coherence across the application, and including explanatory graphics, animations and the use of color, etc.

Following recent fashion, which favors intuitive graphic sequences over large-scale demonstrations, we aimed to produce a teaching module which included the most important concepts related to Plane views. We soon observed that the material generated was much more efficient than conventional material, as all the characteristics of the views, including tracing methodology, graphic invariants and fundamental properties were assimilated extremely quickly. Concepts such as obtaining vanishing points in conical perspectives needed only a little reasoning to be understood easily by people without specific knowledge in the field.

Figure 1 shows a simplified view of the general structure of the Main Menu. It is no coincidence that the structure is similar to that of a book, with code groupings Index, Glossary, Help and Chapters. One of the 
14 Chapters, specifically $n^{\circ} 5$, shows its 5 Sections, and serves to give an understanding of the structure of the other 13 chapters.

In the Routines diagram we have shown all the independent routines, which are organized in a tree diagram, so that there is one tree on which all the common routines depend, and the rest depend on their respective chapter. Chapters 4 and 5 have been shown, as they will be used in this article to show the philosophy of the application; in addition they show the research which lies behind each concept.

In order to understand the structure of the last level, we have also shown the routine which corresponds to the Cut accomplishment process. Lastly, the figure also shows the simplified structure of the Index, Glossary and Help. 
Main menu

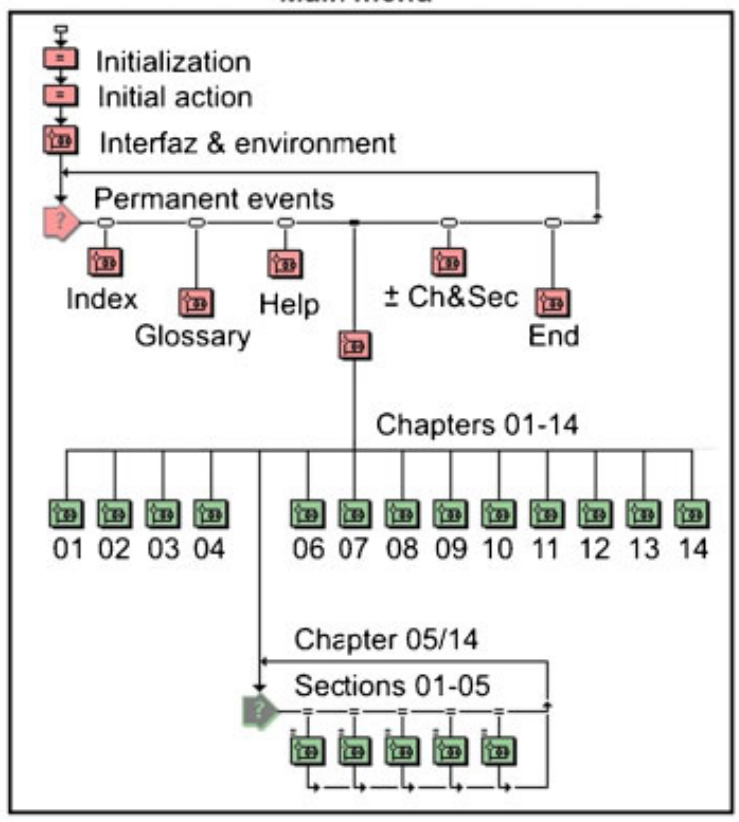

\section{Routines}

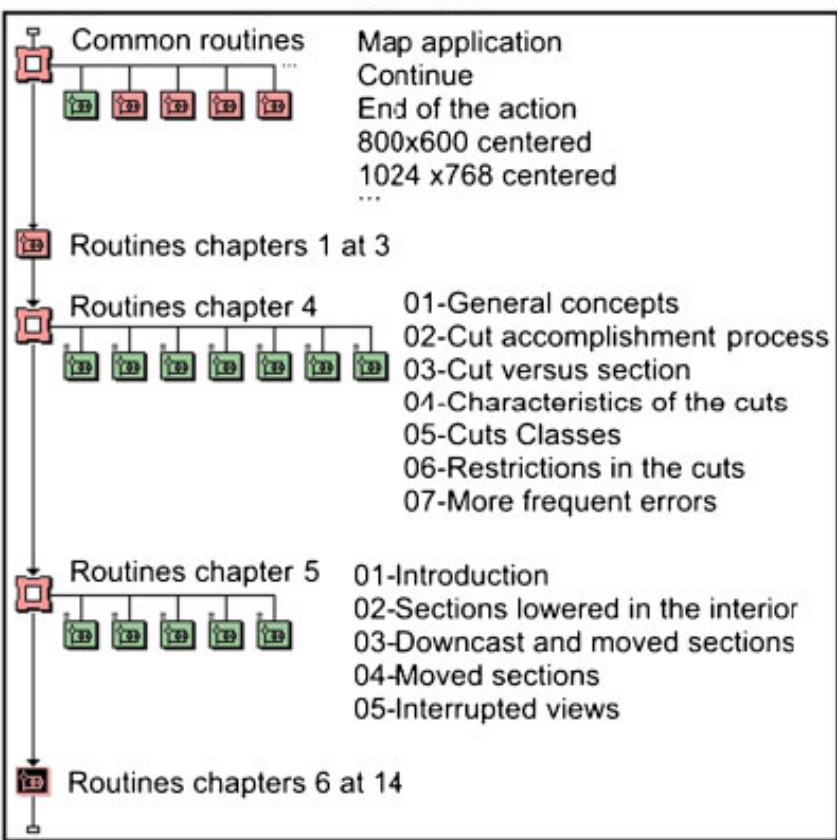

Index

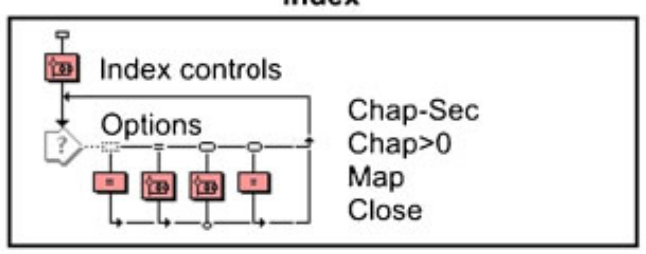

\section{Help}

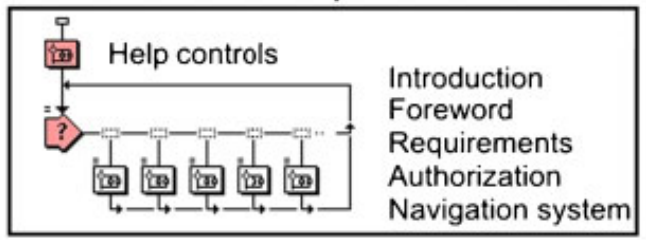

Glossary

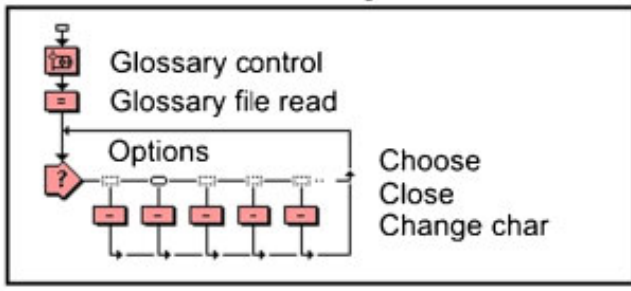

02=Cut accomplishment process

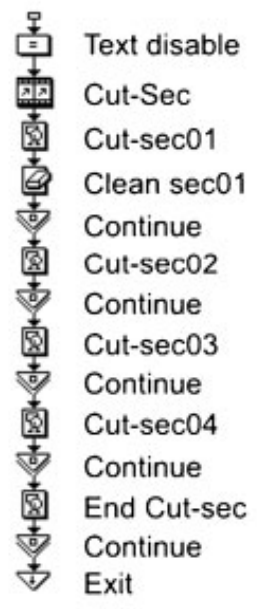

Figure 1. Simplified general diagram. 
The information relating to programming is completed with top level code which includes one of the calculation icons, specifically one of the contents of the Glossary, called Glossary file read (figure 2).

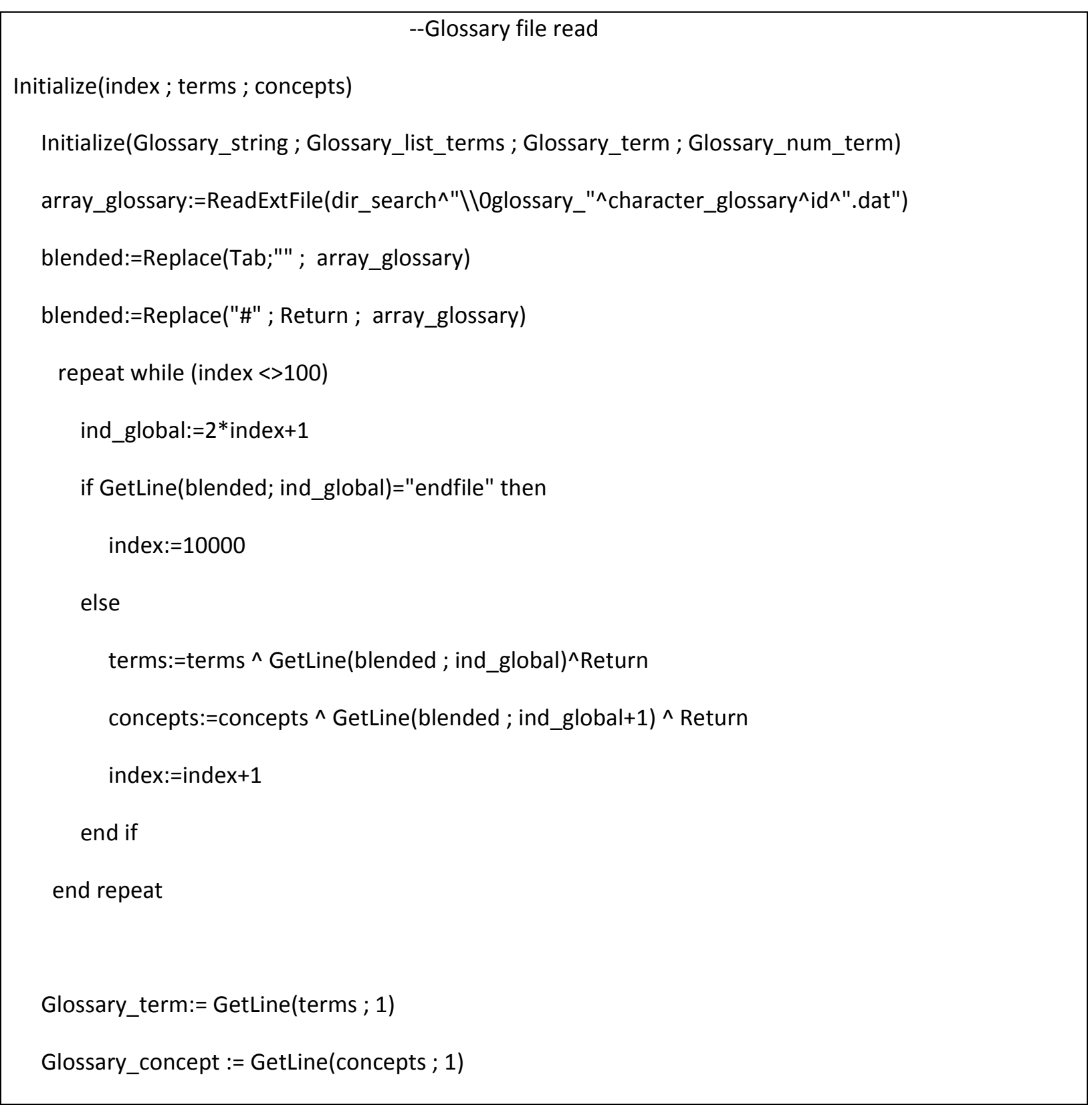

Figure 2. Example of programming code in Authorware. 


\section{DEVELOPED APPLICATION}

The application has 14 chapters, 86 sections and more than 450 animations in formats .avi, .flc and .mov, with synchronized movements and around 1200 static images which are rendered to a high level of quality, with textures, transparencies, and gradients, as well as 1000 hypertext links. This IDA has around 11000 lines of code which allow interaction.

The navigation system of the application is multiple, and the user can enter in various ways: through the general index, which is a textual index such as that found in most books; through the map of the application, which is a general graphic diagram containing all the application's significant elements and which allows swift access to any of the principal themes; sequentially using the Chapter and Section buttons; and lastly, using additional buttons in some sections to reach details or control sequences of actions. The interface has permanent access to two levels of information, while some sections have 4 levels.

Another advantage of the application is that the computing power required is low; the application needs only an operating system such as Windows XP, Windows 2000 or Windows Vista, with resolutions of 1024 x 768 or higher, conditions which nowadays are found in the vast majority of computers.

\section{Solved Cases}

This multimedia application has two clearly different sections. Firstly, all the aspects related to the standardization of technical drawings, in order to give the user all the necessary resources to determine the form and dimensions of any real object, and therefore to check its functioning. The second section deals with the analysis of mechanical elements and the design of mechanisms, which allows the user to reflect on the theoretical models on which it is based, the mechanical elements provided for in industry and its possibilities for use in other mechanisms.

\section{Working}

When the application is run, the main window appears (figure 3). This window has 5 main buttons: Index, Glossary, Help, Map and End. 


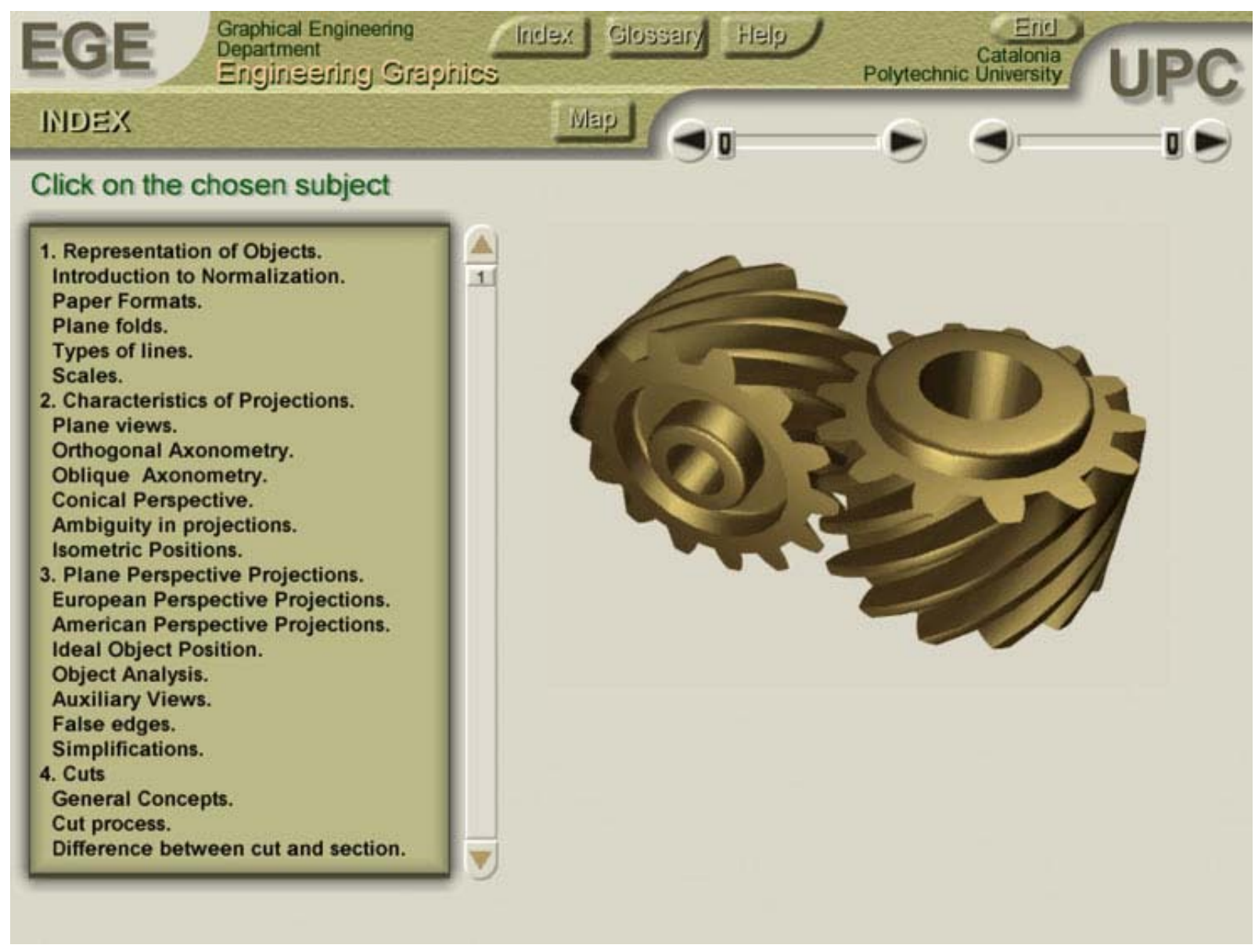

Figure 3. Main window with application index.

-Index:

This option shows the index of chapters. This is the default option when the application is started.

\section{-Glossary:}

This option opens a window with a glossary of the terms used. The screen is divided into three parts: the upper part shows the definition, in the part on the left the user can choose the first letter of the term, and the part on the right shows the list of terms of the glossary (figure 4). 


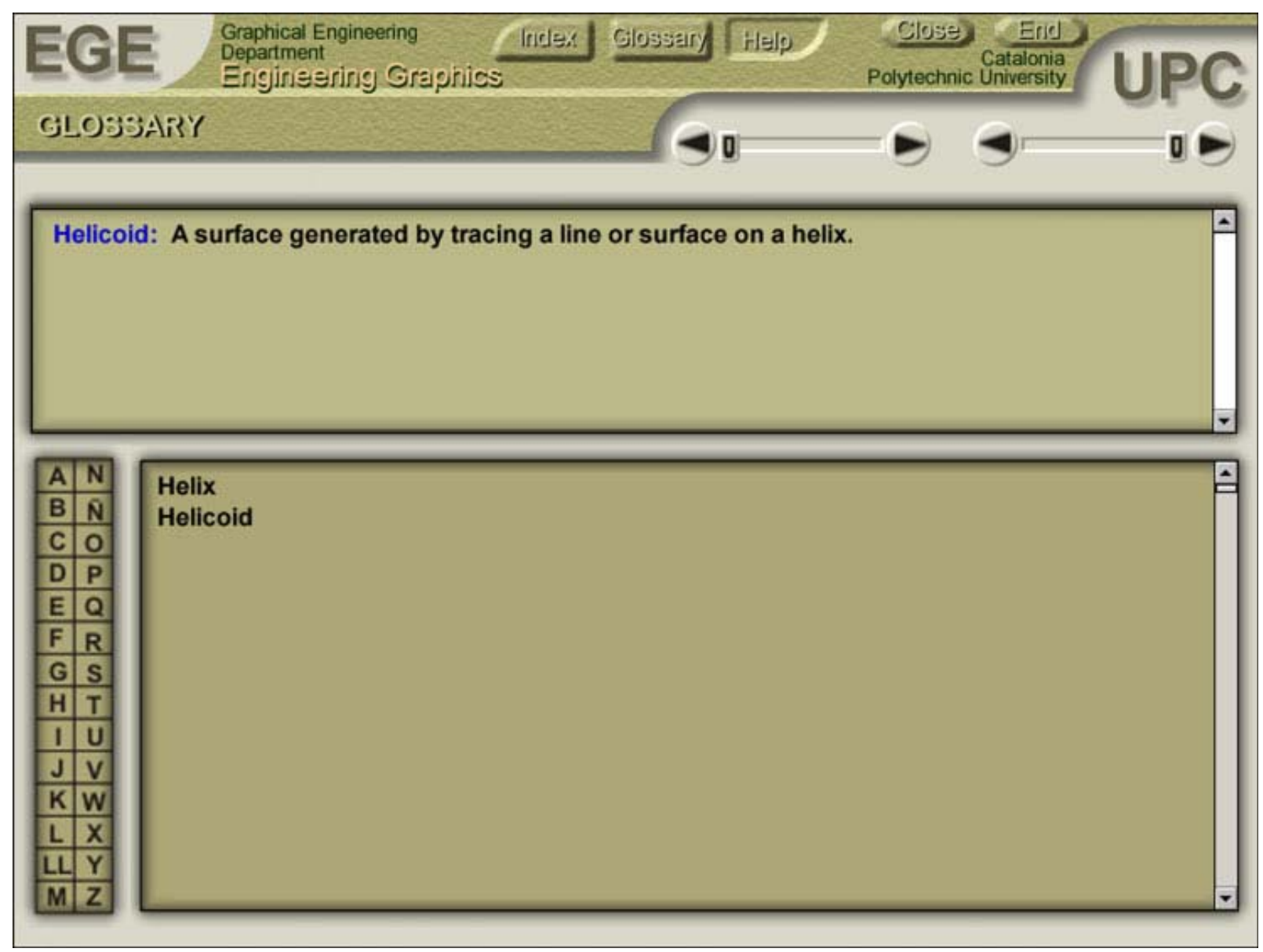

Figure 4. Glossary of terms (Letter H).

-Help:

This option opens a window with help offered by the application, with sections such as introduction, prologue, computing requirements or help with navigation, among others (figure 5). 


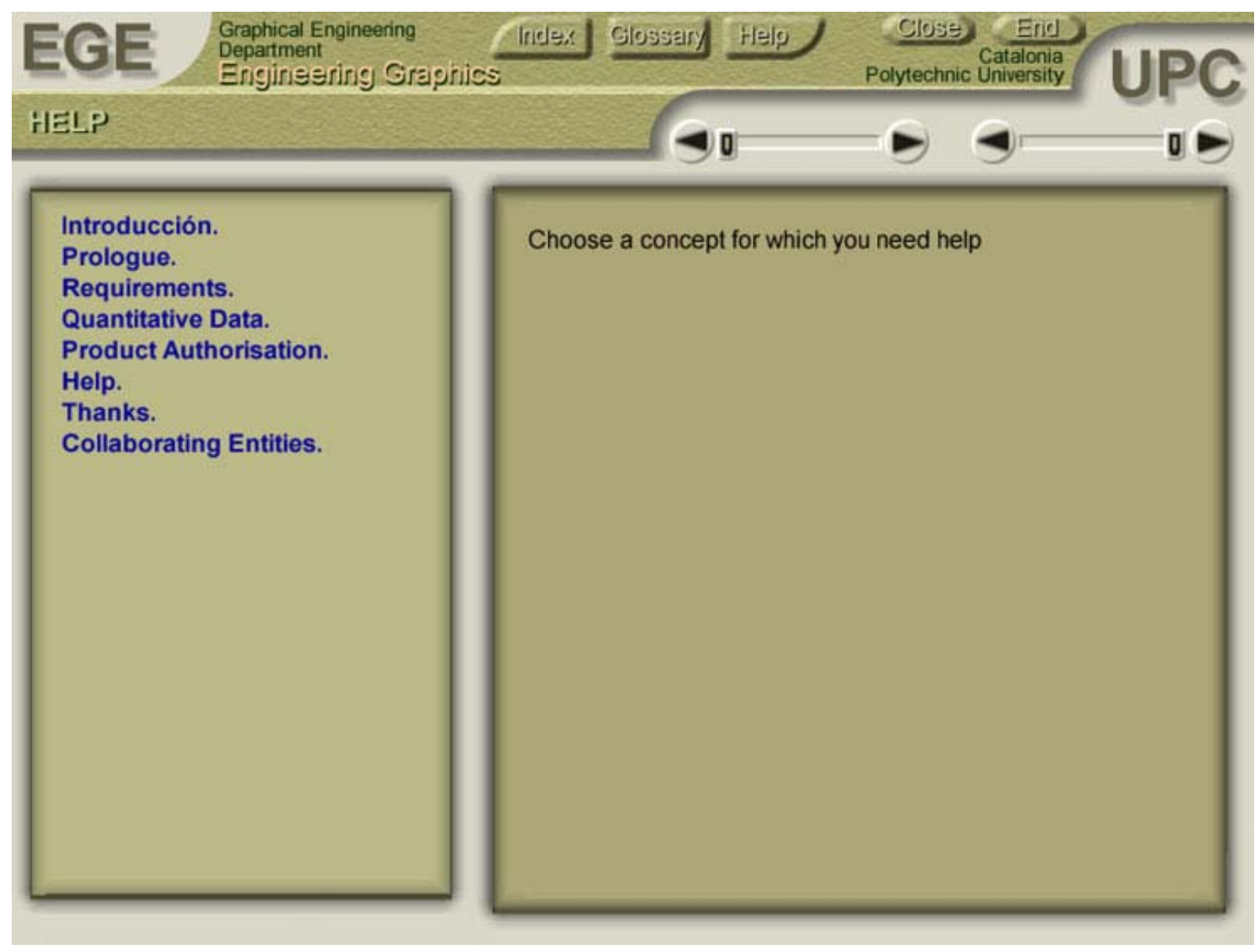

Figure 5. Help window.

-Mapping view: This option shows a view of the thematic map of the application (figure 6). 


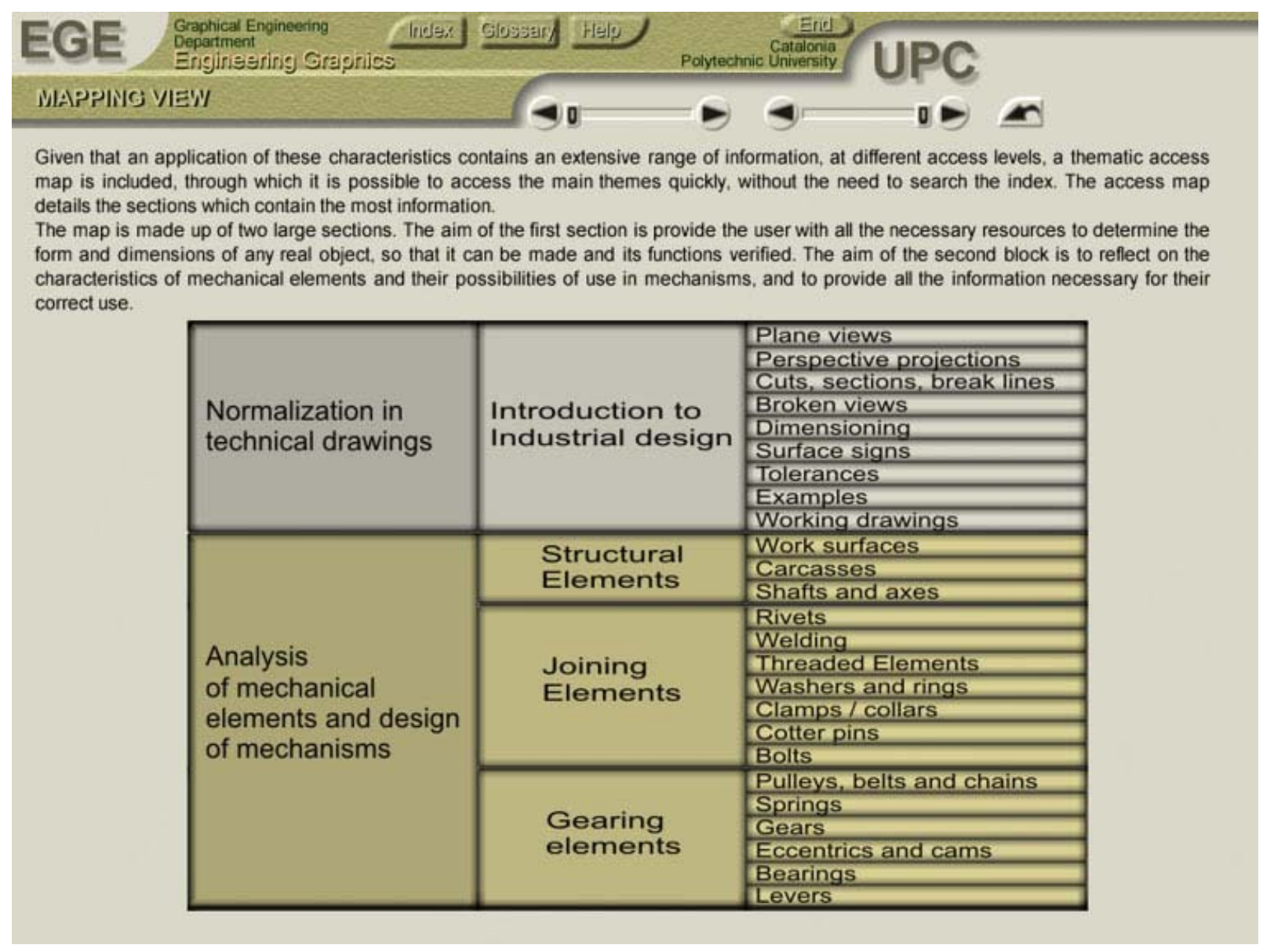

Figure 6. Mapping view.

To show the working of the application, we present a sequence of images and their justification. As an example, two small but significant parts have been chosen; they give a clear idea of the way in which each concept has been dealt with. The first is a complete part of chapter 4 (Cuts) and the second a complete part of chapter 5 (Sections and break views).

When chapter 4 is opened, either from the index or by using the control buttons, the image shown in figure 7 appears, which is the entry point for chapter 4 . It contains a brief introduction to the chapter, the purpose of which is to rationalize the way information about the interior of objects is presented. This function is performed in industry using cuts and sections.

Given that the essentials of cuts and sections are the same, this is the ideal place to facilitate the 
assimilation of the concept of section and the difference between cuts and sections.

This screen (figure 7) gives access to 6 hyperlinks or actions. The first two clarify the concepts of cut and section, showing the relationship between them and their differences, while the four remaining actions refer solely to cuts.

The following shows the first action, Process of making a cut, which allows us to understand to philosophy of the whole application.

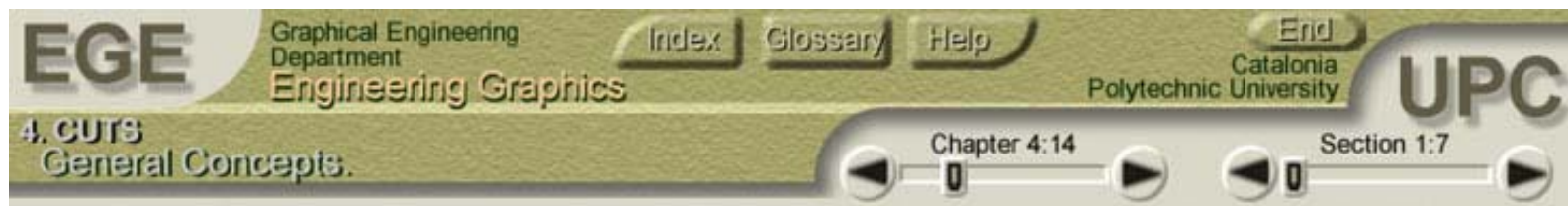

The interior elements of the objects are difficult to interpret, as they are not completely visible from any of the views used in the perspective projections (1st of 3 rd dihedral).

The use of hidden lines to ease interpretation of these elements is inefficient and confusing. Therefore, the system uses additional resources which make these hidden zones visible, making it easier to interpret and define them.

The cut is an imaginary process through which part of the interior of an object is shown, in order to clarify its spatial geometry in zones which are not defined, as they are not visible from the exterior.

In an attempt to unify criteria and give the system a universal language, a set of rules and procedures has been established. The following aspects are considered:

Process of making a cut.

Cuts and sections. Differences.

Characteristics of cuts.

Types of cuts and their uses.

Restrictions of cuts.

Most common errors in cuts.

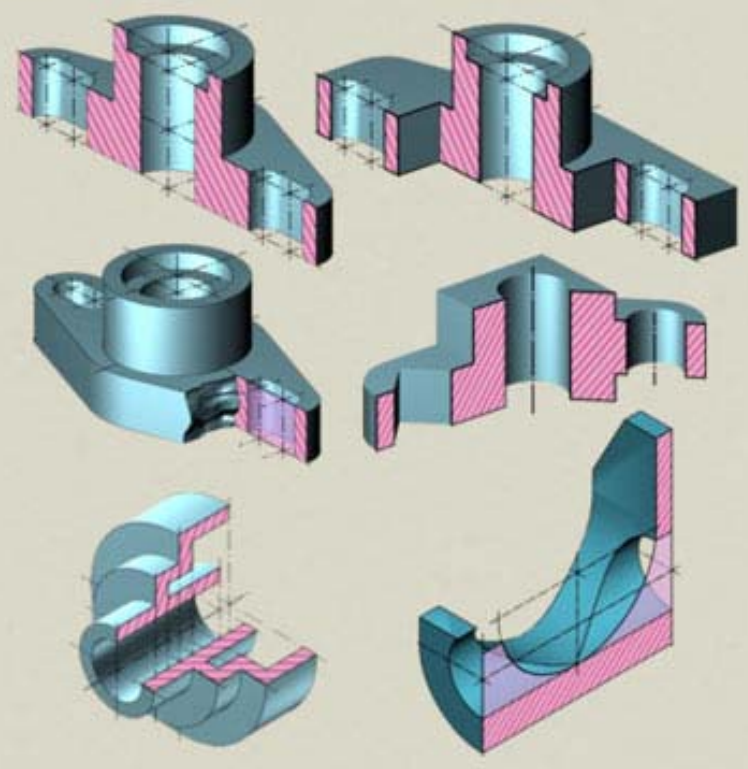

Figure 7. Main window of cuts and sections.

The first action leads to the following window (figure 8), where two actions are offered when the appropriate object has been chosen to introduce the concepts of cuts and sections. 


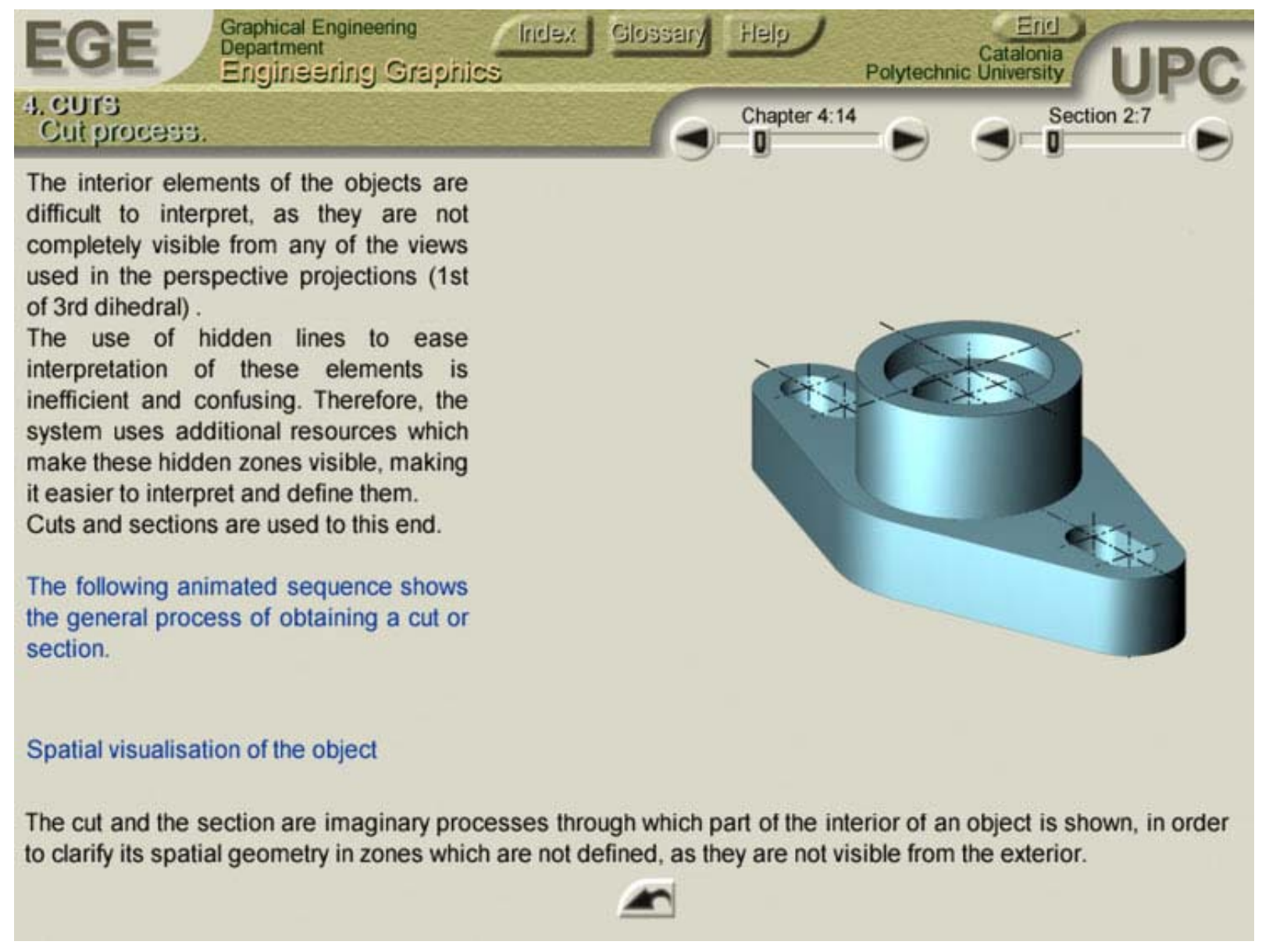

Figure 8. Process of generation of cuts and sections.

The action Spatial visualisation of the object has the aim of allowing the user to perceive as well as possible the geometric form of the object. It leads to an animation showing the object which has been prepared with the desired characteristics:

1) The object should be zoomed out, so that using a controlled movement the different parts of the object can be shown, because a static position does not allow the user to appreciate its geometry.

2) It should be ensured that the camera focuses all the necessary parts at some point in time, as movements such as a simple rotation on the $\mathrm{Z}$ axis would not show the lower part of the object, and would not fulfill the desired purpose.

3) Once the object has the appropriate size, its movement should be cyclical, as this animation will be repeated indefinitely until the user assimilates the geometry of the object and decides to finish the 
action.

4) It is important to control the illumination, as otherwise there would be dark areas during movement which would prevent a clear view of the object from different angles.

The movement is made up of two parts, the first of which is not cyclical, as it is a zoom out, as in point 1 . To achieve the desired animation, a synthetic camera has been placed so that it is pointing at the centre of the scene and the object is leaning slightly to the right, which has previously been statically illuminated using various spotlights, slightly towards the right, as in point 4.

The initial camera position is point A (a1, a2, a3), and it is initially focused on the centre of the scene. After the zoom the focus passes to the centre of the object $B\left(b_{1}, b_{2}, b_{3}\right)$, where it remains until the second animation is completed.

To maintain the desired alignment, the camera is situated in a point $C$ in line with the straight $A B$, which forces it to adhere to the equation of the straight $\mathrm{AB}$.

A previous step is to obtain the vector of the line in the space (v1, v2, v3) such that:

$v_{1}=\left(a_{1}-b_{1}\right) \quad v_{2}=\left(a_{2}-b_{2}\right) \quad v_{3}=\left(a_{3}-b_{3}\right)$

Given that the distance between A and B is:

$D=\sqrt{\left(a_{1}-b_{1}\right)^{2}+\left(a_{2}-b_{2}\right)^{2}+\left(a_{3}-b_{3}\right)^{2}}$

For a point $\mathrm{C}$ with coordinates $(\mathrm{x}, \mathrm{y}, \mathrm{z})$, the contour conditions give the equations:

$\frac{\left(x-b_{2}\right)}{v_{1}}=\frac{\left(y-b_{2}\right)}{v_{\mathrm{D}}}=\frac{\left(z-b_{\mathrm{Z}}\right)}{v_{\mathrm{B}}}$ (Equation of the line in 3D)

As a second condition of the contour, the distance to B must be double: 
$2 D=\sqrt{\left(\mathrm{x}-\mathrm{b}_{1}\right)^{2}+\left(\mathrm{y}-\mathrm{b}_{2}\right)^{2}+\left(\mathrm{z}-\mathrm{b}_{3}\right)^{2}}$ (Double distance to the lens)

The movement of the camera in the first stage is one segment, which is traveled in two seconds, generating 60 images (30 images per second), and the camera stops at point C.

The process is similar for the lens, as in the same period of time it moves the segment from the centre of the scene W ( $\left.\mathrm{w}_{1}, \mathrm{w}_{2}, \mathrm{w}_{3}\right)$ to the centre of the object B ( $\left.\mathrm{b}_{1}, \mathrm{~b}_{2}, \mathrm{~b}_{3}\right)$, such that the second animation is fixed on B.

To ensure points 2 and 3, a spatial trajectory is generated for the camera from point $\mathrm{C}$ and moving around point $\mathrm{C}$, in order to make this part of the movement cyclical. On this occasion the trajectory is divided into 3 sections, choosing five more points through which the camera passes, keeping the lens in point B at all times (figure 9).

The first section is the part of the curve which joins points 1,2 and 3; the second section is the part of the curve which joins points 3, 4 and 5, and the third part closes the curve, starting at point 5, passing through point 6 and ending at point 1.

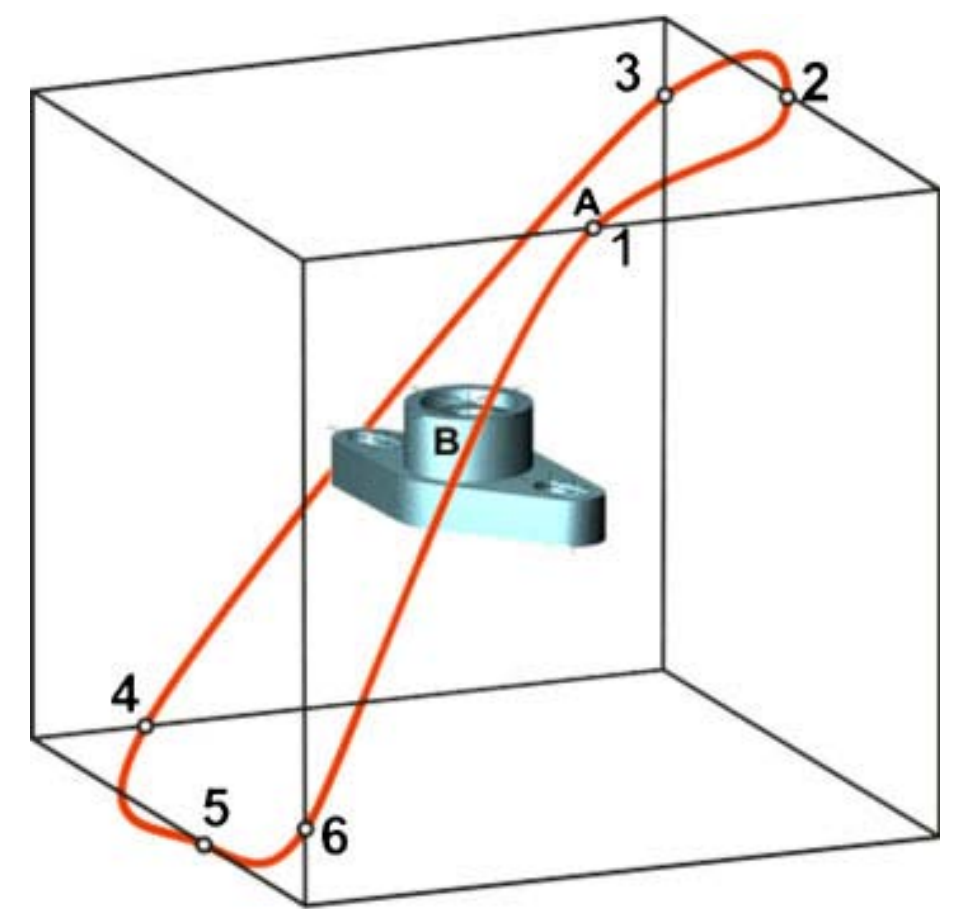

Figure 9. Spatial vision of the trajectory of the camera. 
In order to control the movement of the camera and make it smoother, the trajectories of the positions of the camera were separated in values $\mathrm{X}(\mathrm{t}), \mathrm{Y}(\mathrm{t})$ y Z (t), imposing on the sections the contour conditions:

a) The curve in each section corresponds to a quadratic equation as a function of $t$ for each of the three spatial directions (first contour condition):

$$
\begin{aligned}
& X(t)=a t^{2}+b t+c \\
& Y(t)=d t^{2}+e t+f \\
& Z(t)=g t^{2}+h t+i
\end{aligned}
$$

As an example we show the form of the curve of heights $Z(t)$, which shows the smoothness of the joins, the slopes at each point and the slope of the extremes, to ensure continuity (figure 10). The curves for $\mathrm{X}$ and $\mathrm{Y}$ are of the same type.

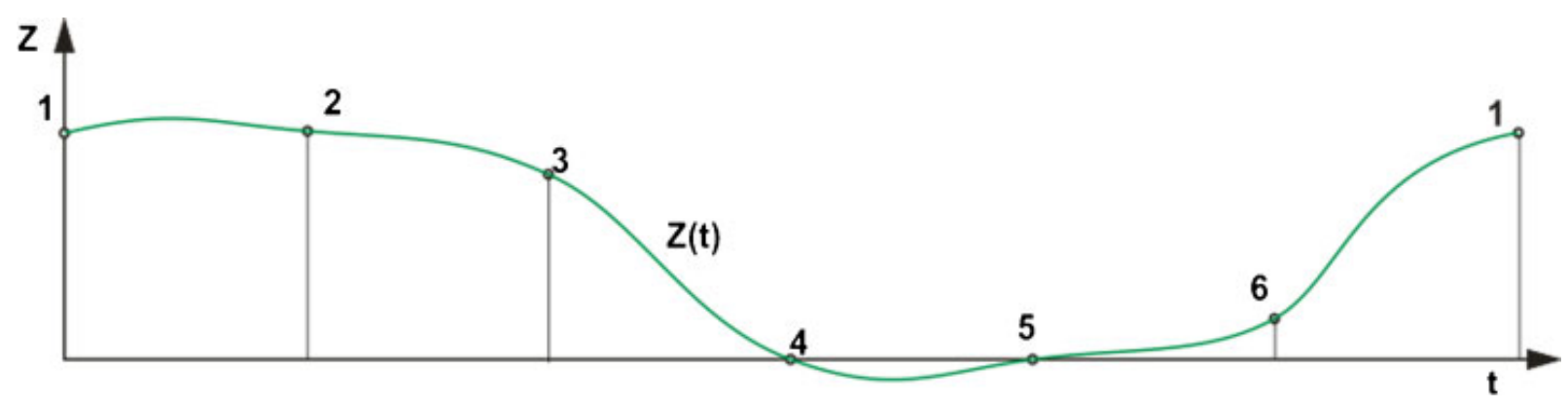

Figure 10. Curve of heights in the trajectory of the camera.

b) The sections are formed by three points of the six selected through which the curve passes (second contour condition).

c) At each intermediate point of the section, the value of the tangent is that of the segment which joins the end points (third contour condition).

d) The curve is continuous, so the tangents at the start and end points are equal (fourth contour condition) which is met by equaling the first derivatives of the curves at these points). $X^{\prime}(t)$ at the end point of the 1st section $=X^{\prime}(t)$ at the start point of the 2nd section

e) The last point of the curve (the 6th) has an equal tangent to that of the 1st point (fifth contour condition). In these conditions, the system is determined by three quadratic sections of curve (figure 
9), which are smoothly joined, passing through all the points defined by the trajectory of the curve (local Splines). The following figure shows a sequence of the result from the corresponding animation (figure 11), in which the interface has been deleted so that it is clearer.

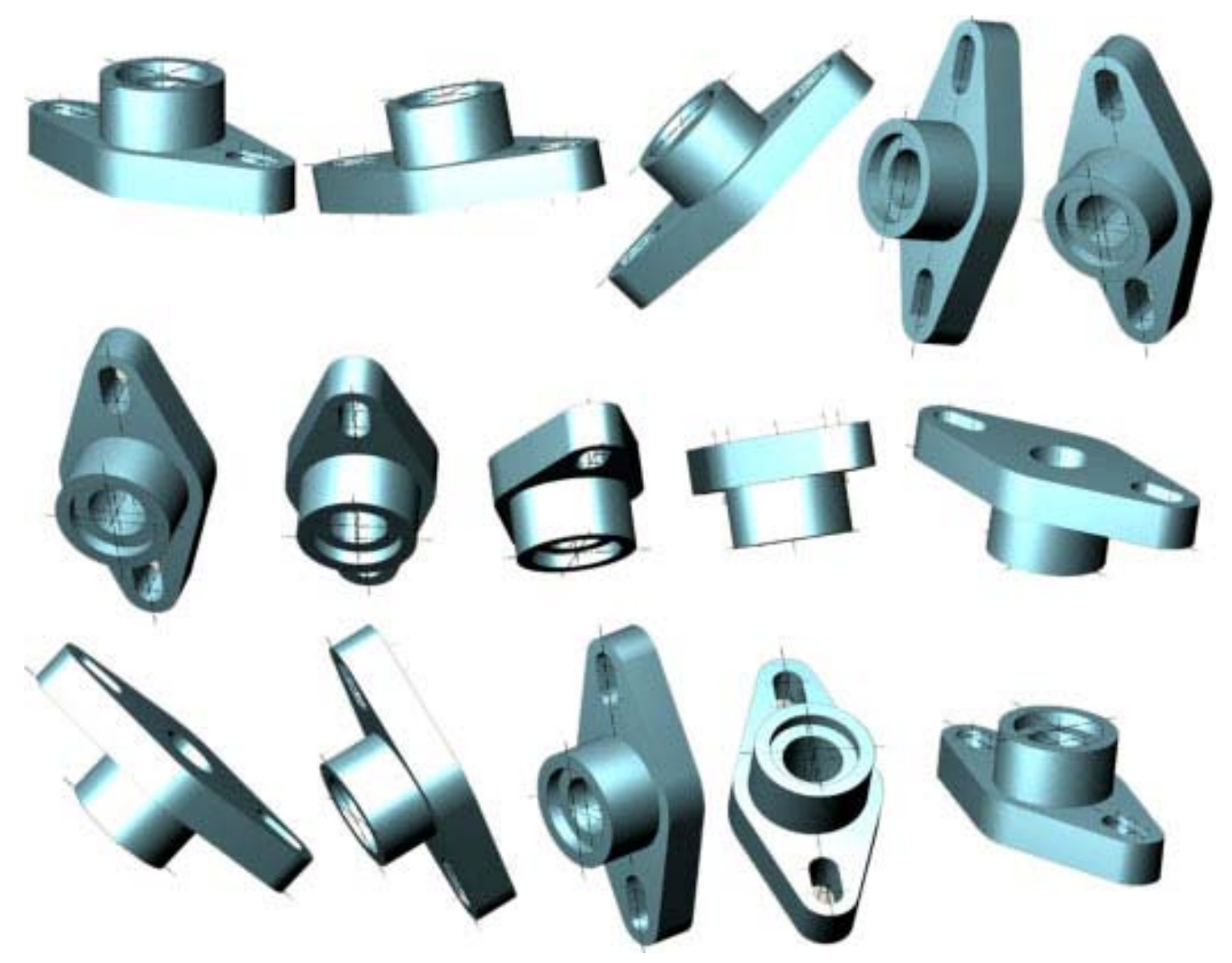

Figure 11. Extract of the animation designed to assimilated geometry of the object.

The second action taken from the image described in figure 8, labeled The following animated sequence shows the general process of obtaining a cut or section, shows the mental process which leads to making a cut or a section. It is made up of various stages, which are described as follows:

a) The object is cut through a vertical semitransparent plane which moves downwards on the same plane as the main axes, indicating the trajectory of the cut (figure 12).

b) The front part of the object is separated, moving in the direction of the Y axis. Previously, the area of the material has been marked with lines, to differentiate it from the rest. Sections a) and b) form part of the same animation. Once the parts are separated, the action can be paused by clicking the mouse (figure 13). c) After clicking, the front part of the object disappears, leaving the rear part of the object visible. The 
action is paused until the next click (figure 14).

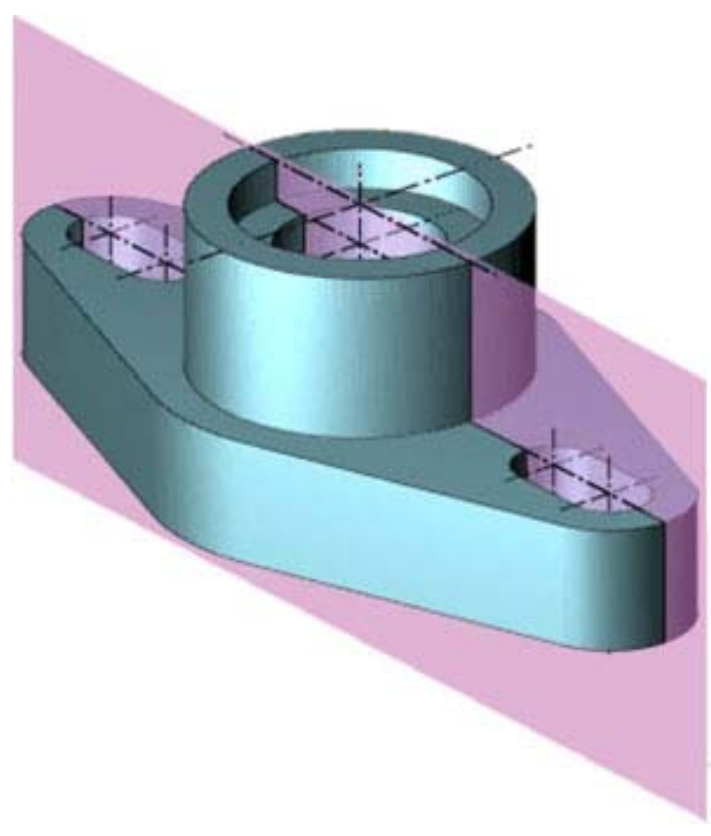

Figure 12

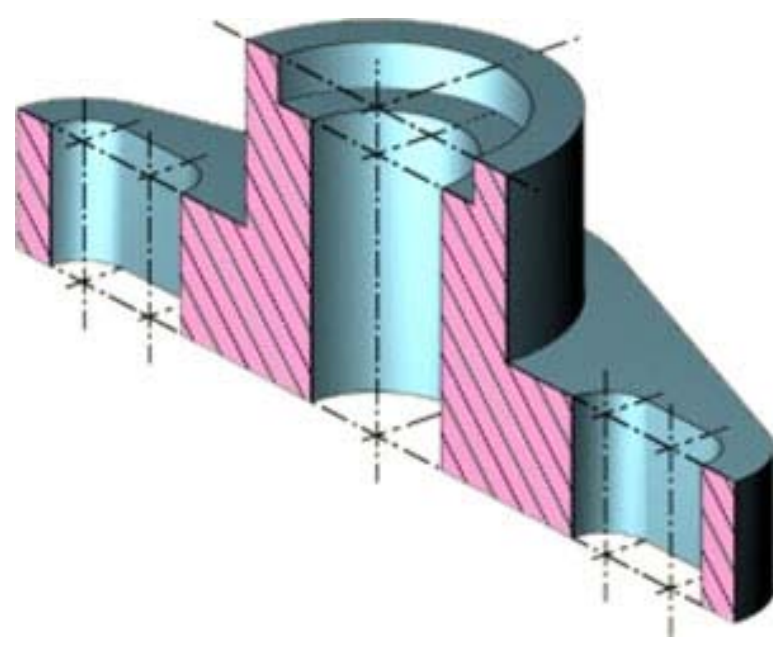

Figure 13

d) After the next click, the visualization direction appears (figure 15), which highlights the origin of the projection to obtain the cut or section.

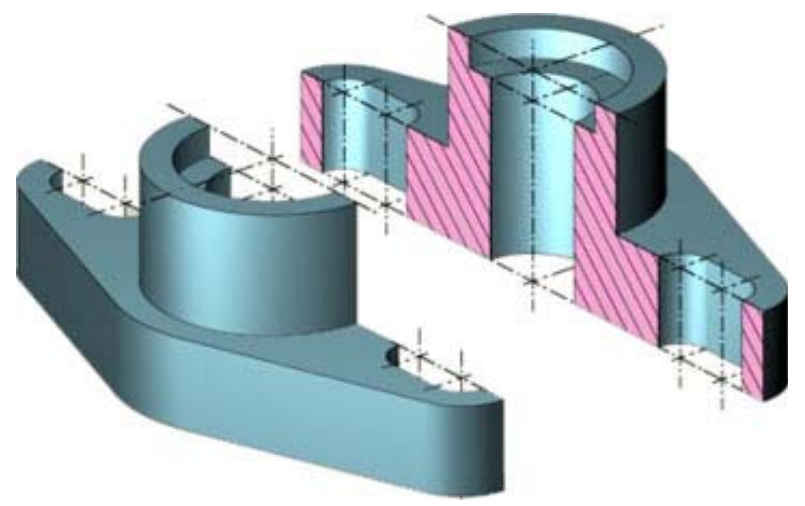

Figure 14

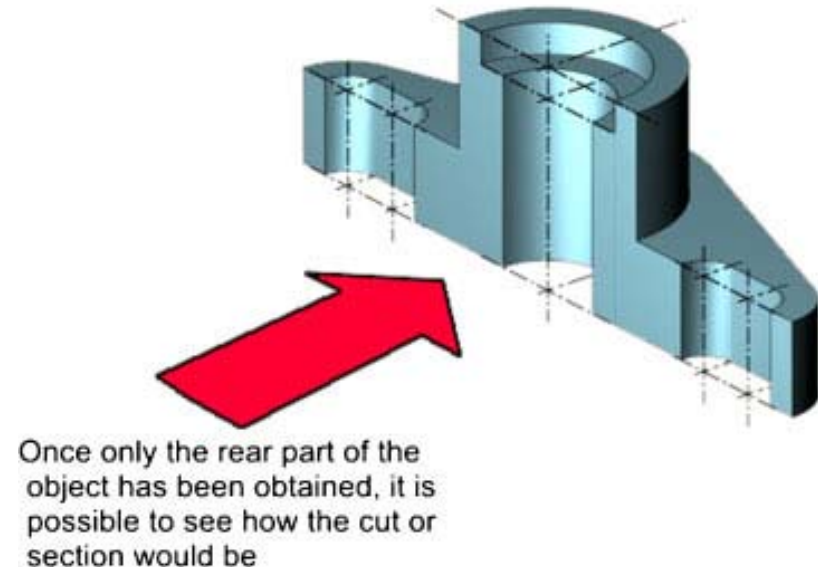

Figure 15

e) In the following step, the projection of the object is drawn in the plane of the cut, making sure that transparencies allow the user to distinguish the parts in which the plane is in contact with the material, so that the cut (figure 16) can be clearly differentiated from the section (figure 17). 


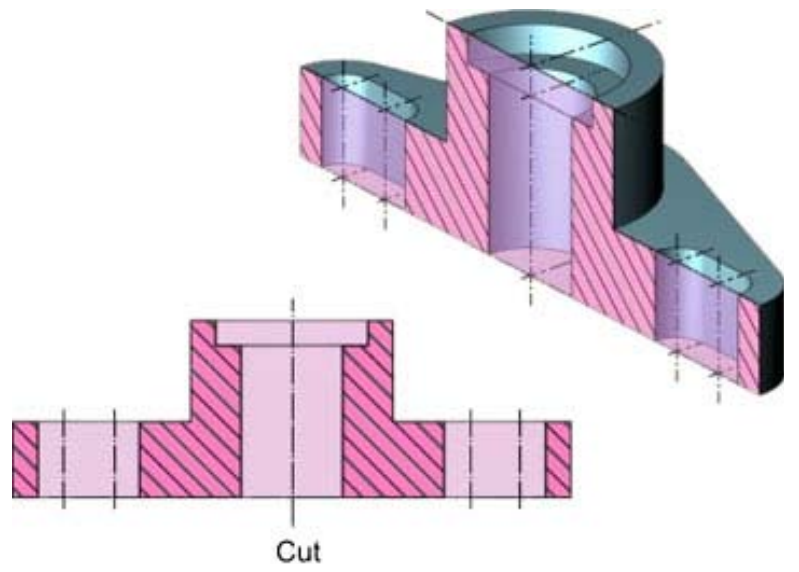

Figure 16

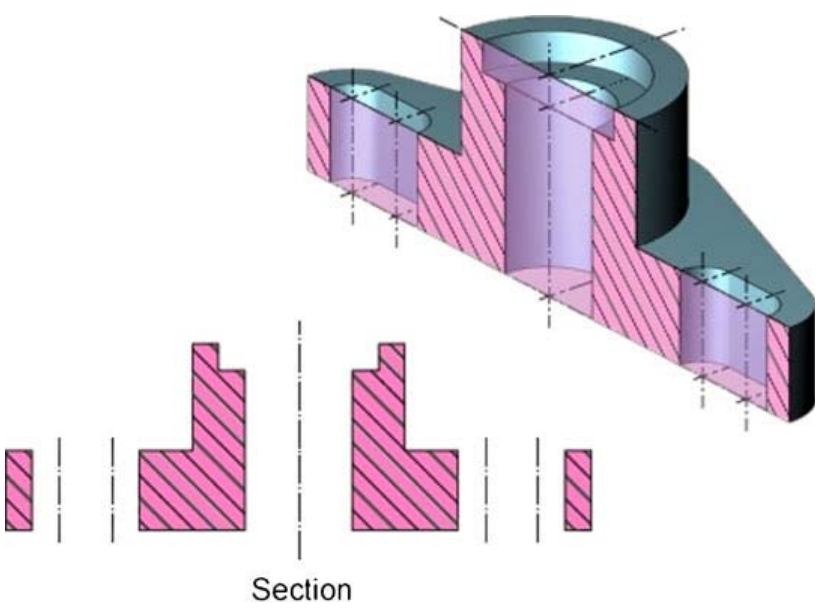

Figure 17

The following screens show the sequences relating to chapter 5 .

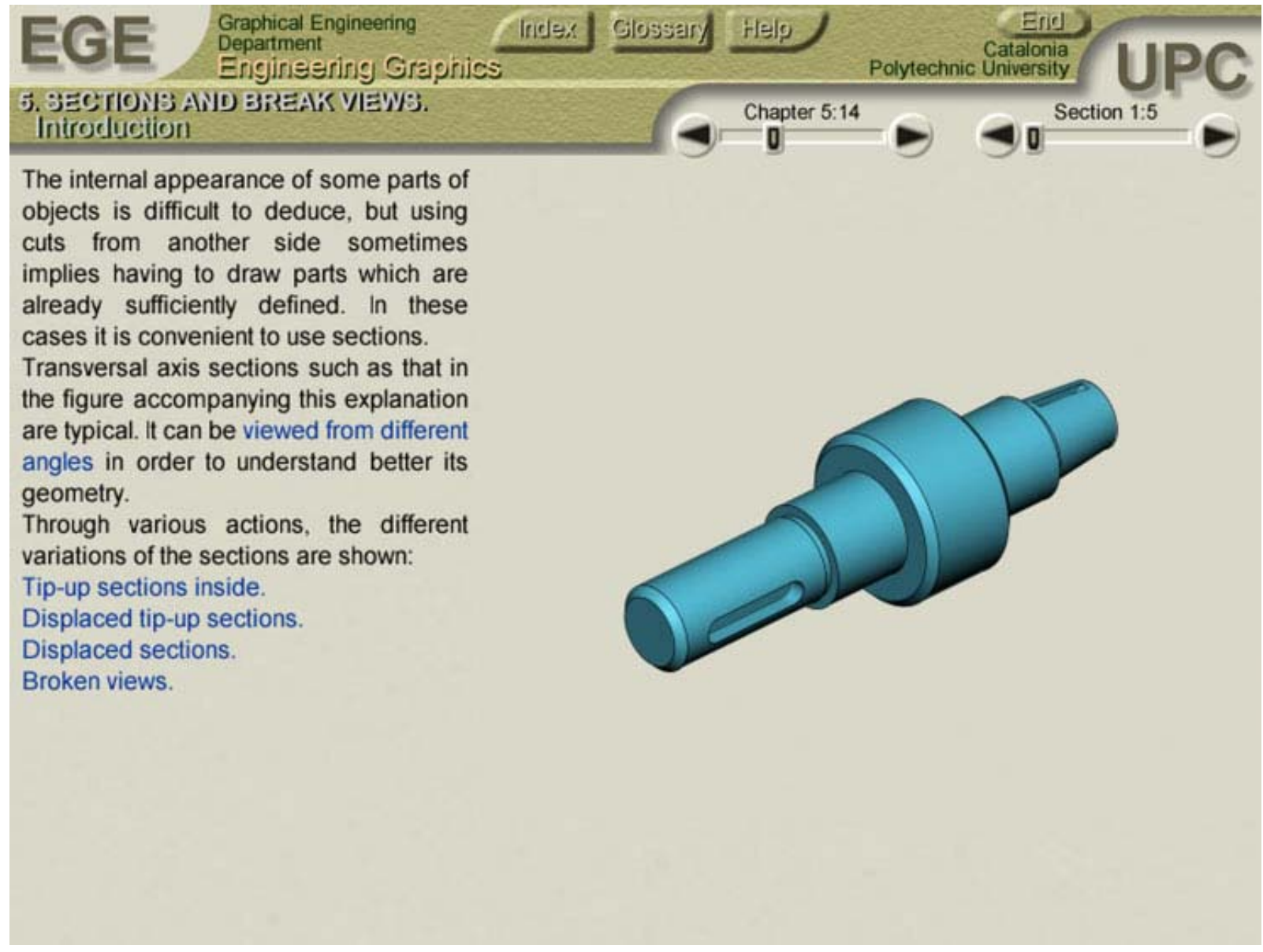

Figure 18. Window of the chapter on sections and break views (section 1:5). 


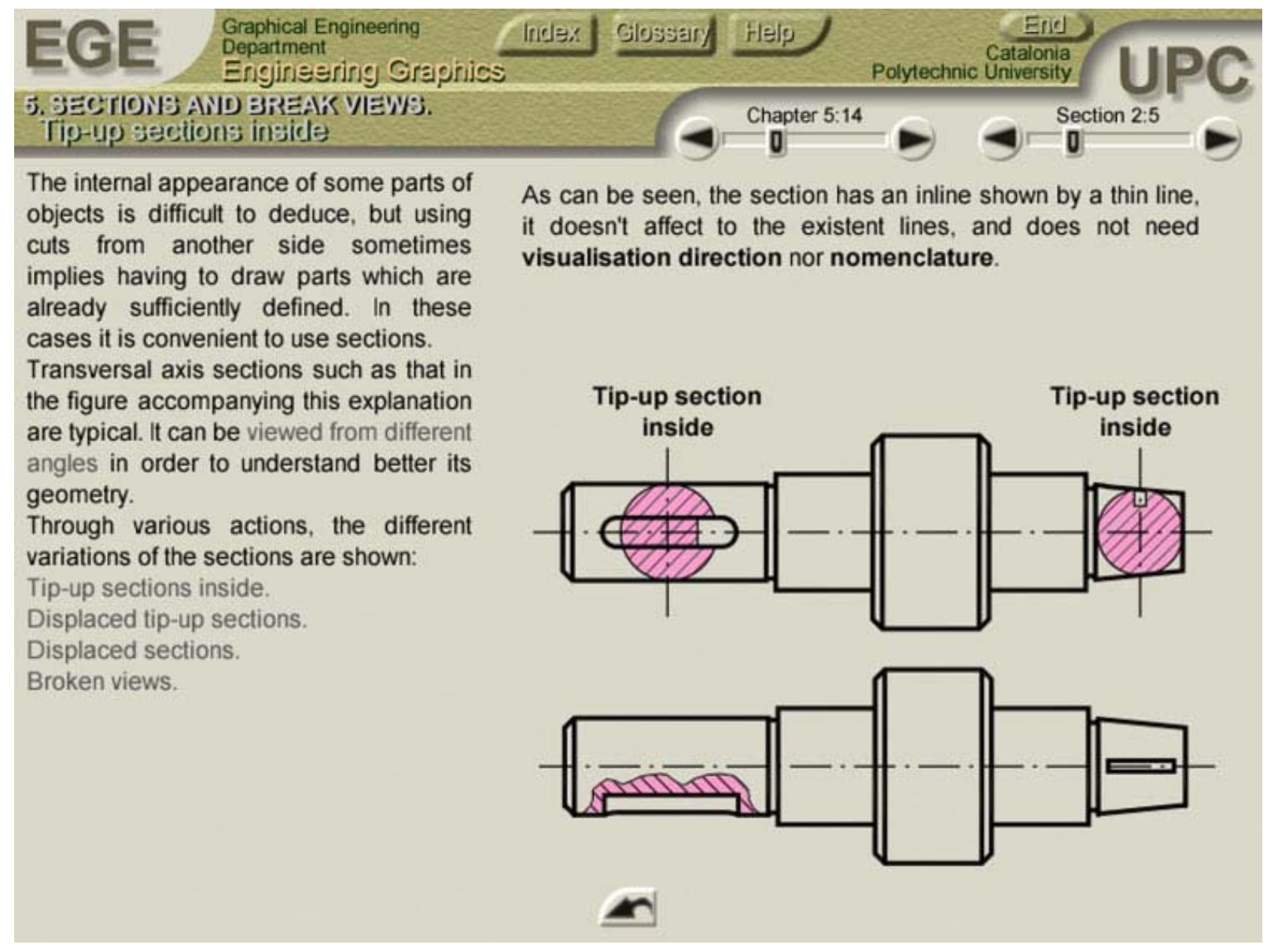

Figure 19. Window dealing with interior tip-up sections (2:5). 


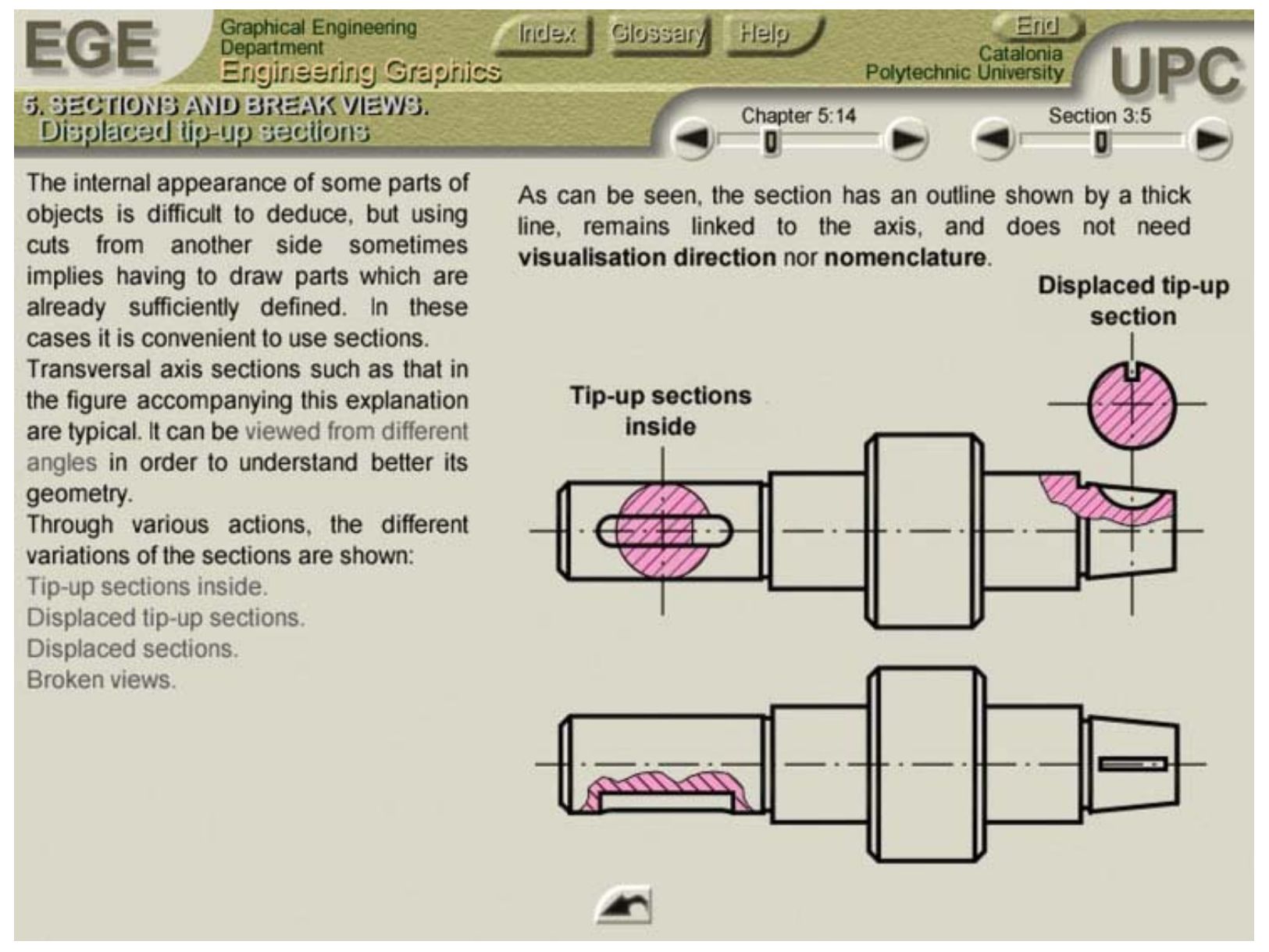

Figure 20. Window of tip-up and displaced sections (3:5). 


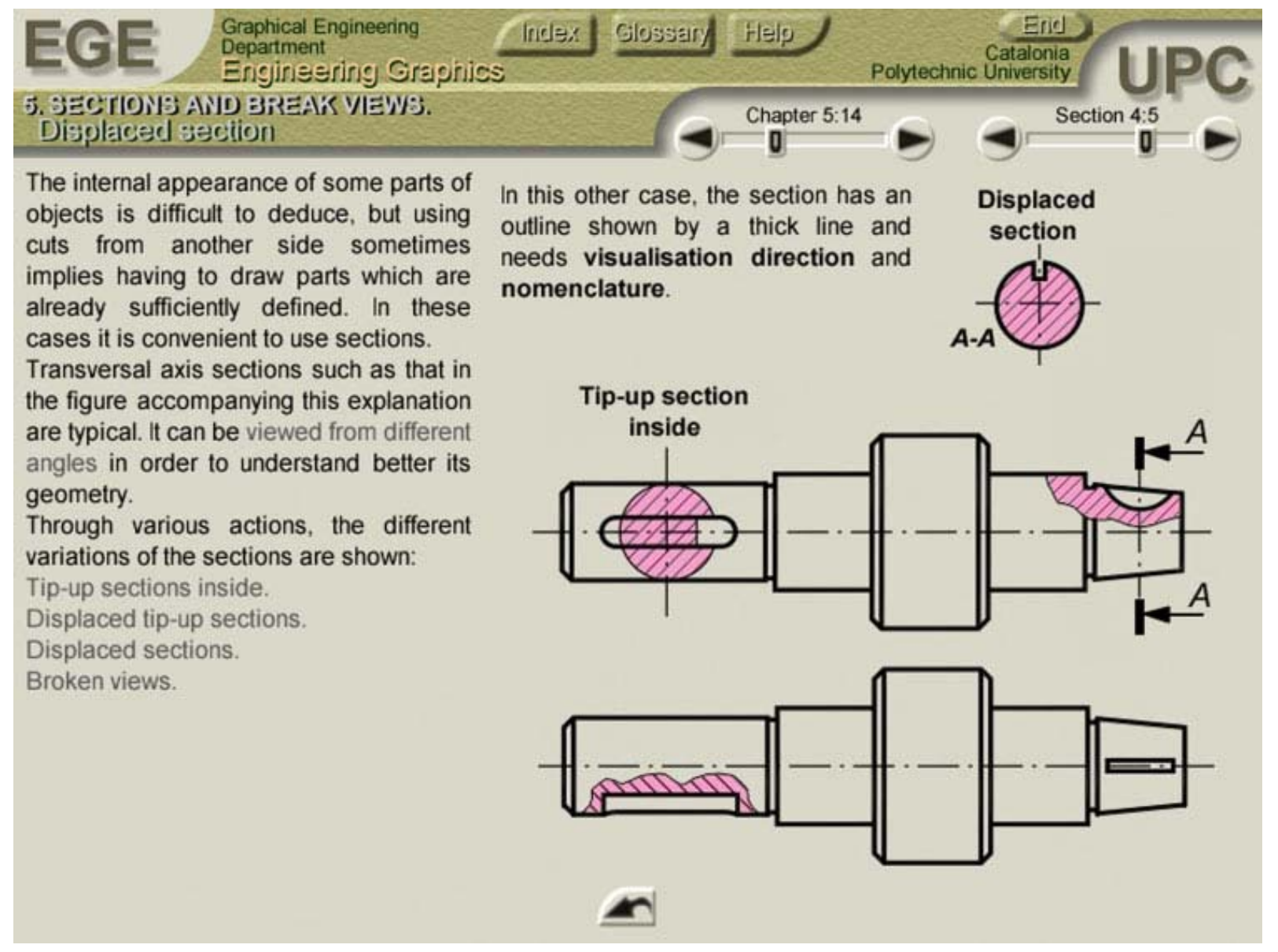

Figure 21. Window of displaced sections (4:5). 


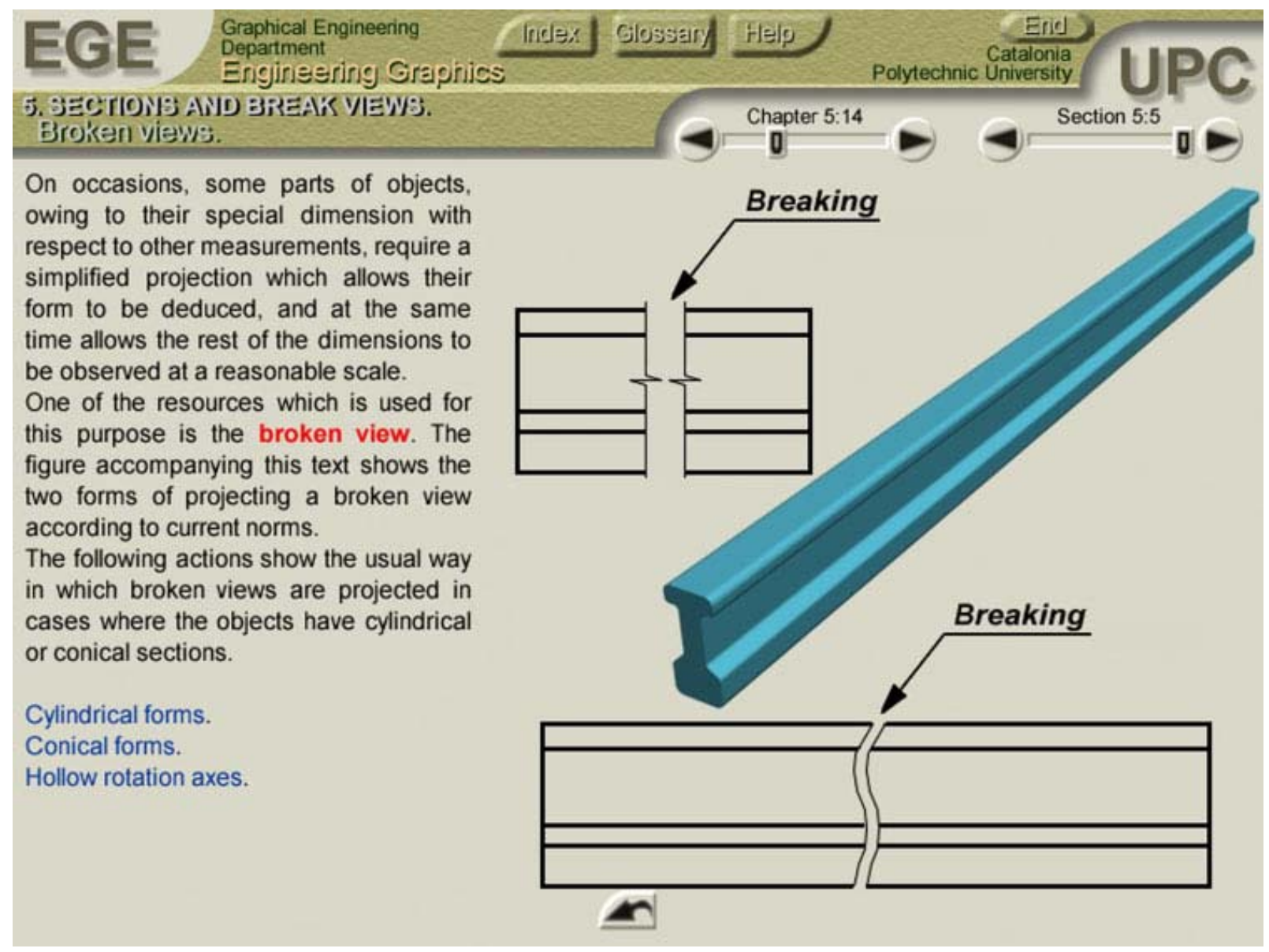

Figure 22. Window of break views (5:5). 


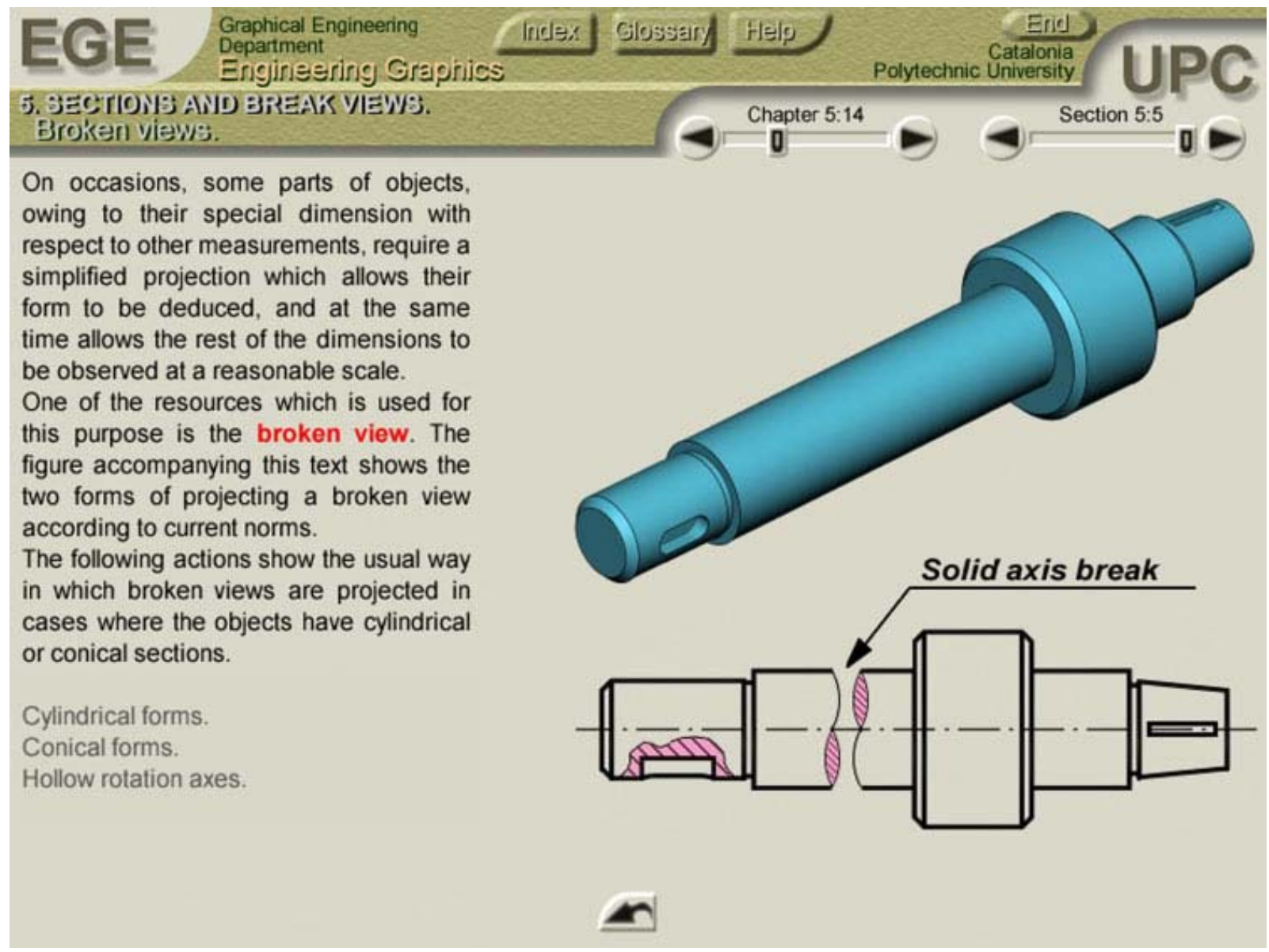

Figure 23. Subsection of different cylindrical forms in the break view section (5:5). 


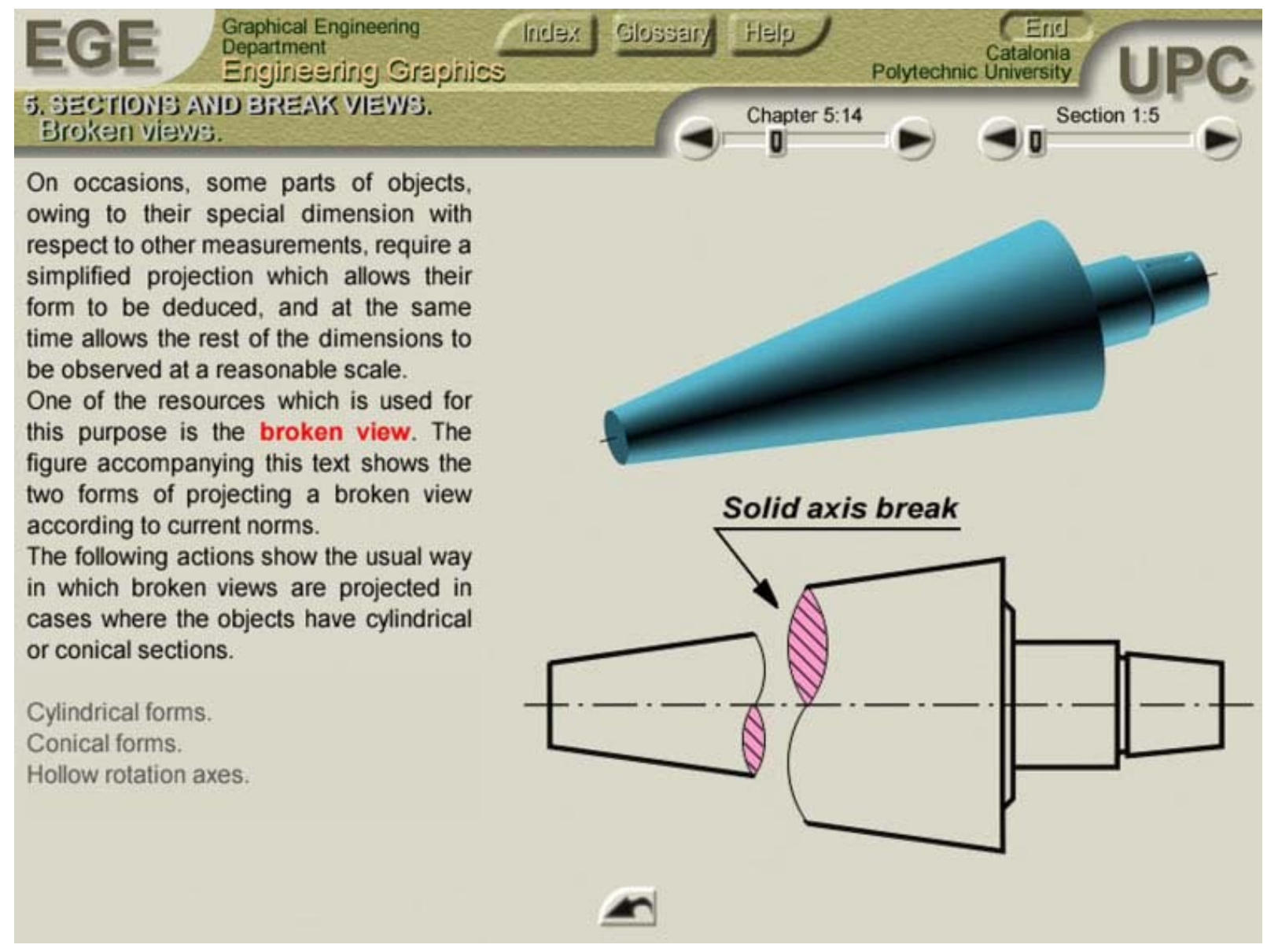

Figure 24. Subsection of conical forms in the break view section (5:5). 


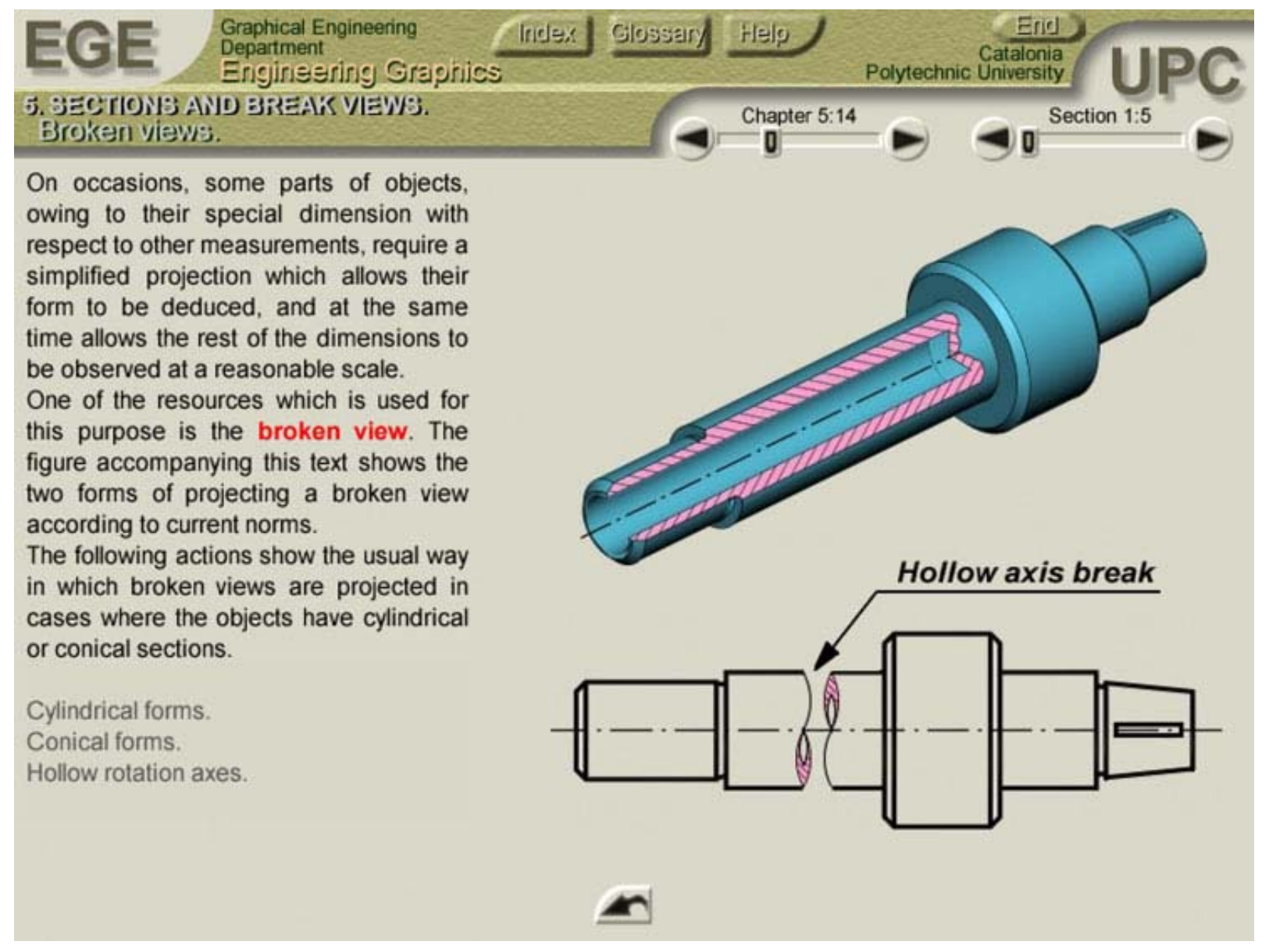

Figure 25. Subsection of hollow axis breaks in the break view section (5:5).

\section{ASSESMENT OF THE APPLICATION}

The assessment of the teaching application (IDA) has been carried out on two levels:

On an internal level, it has been used in teaching courses in Engineering Graphics at the School of Industrial and Aeronautical Engineering at the Technical University of Catalonia, in Terrassa (Barcelona, Spain) during two consecutive terms in the 2007-2008 academic year (and is still being used).

In order to contrast the effectiveness the IDA, this research group, working in conjunction with the Statistics Department of the Technical University of Catalonia, produced a questionnaire which was given to the 512 students who passed the course in order to obtain impartial responses. Of these, 420 (82\%) completed the questionnaire. 
The questionnaire was made up of 5 questions, in which the students had to assess the application using a scale of $1-5$ (1= very unsatisfactory, $2=$ unsatisfactory, $3=$ indifferent, $4=$ satisfactory, $5=$ very satisfactory). The questions used in the questionnaire and the results obtained are shown below. They show a high degree of satisfaction.

- $\quad$ Overall assessment $($ mean $=4.8)$

- $\quad$ User friendliness $($ mean $=4.6)$

- $\quad$ Easy browse $($ mean $=4.8)$

- Interaction clear and understandable (mean $=5.0)$

- $\quad$ Speed of response $($ mean $=4.9)$

On an external level, the IDA was given to experts in the field in another 5 centres of the university, and also from other Spanish, Italian and Latin-American universities, so that they could use the application and suggest any possible improvements. In general terms there was a great deal of interest; many universities are now using the application and some have provided important information to improve specific aspects. Other prestigious university bodies have also shown interest in the application, such as Education Science Institutes and Professional Colleges and Libraries.

\section{USABILITY AND LIMITATIONS}

This IDA is an exceptional tool in the hands of teachers, professionals and design experts, as it includes not only the necessary content to cover different topic areas, but also the conceptual basis for their inclusion. In the same way as in any research process, first is the problem and then there is a deep analysis of the subject, which requires a thorough search for information, a detailed analysis of this information and an assessment of its effectiveness and impact. The solution in then considered using various reasoned proposals, in order to choose the sequence which best combines efficiency with integration in the environment generated by the application (and this is done with significant reinforcement, which implies using high-quality graphics and animations). This is a new teaching method, which has all the advantages of conventional media, and very few of their limitations. 
Among the current limitations are those relating to the hardware used with the application; the animations and images used are not scalable, and visual presentation media do not have uniform characteristics. It should be borne in mind that this is ideal material to be used with a projector in the classroom. Another limitation relates to the remote use of the application, as some of the animations used are very large and complex (for example, the internal functioning of a complete combustion engine or of a steam engine). However, despite these limitations, the application is being used in an installation with a dedicated server accessible from a local area network, and this experience will be useful in solving minor problems which do not occur when network speeds allow the animations to run without previous loading of files (for example, blocking a file while a modification is made by a remote user, and then unblocking it once the modification has been made).

In addition, another limitation is that the software only works on a Windows platform, and at present it is not envisaged on a different operating system (for example LINUX).

\section{THANKS}

The authors wish to thank Carles Farré Desongles and Francisco Rodríguez García for their help in developing the Interactive Didactic Application.

\section{CONCLUSIONS - FUTURE WORK}

- The team has incorporated Computer Assisted Teaching (CAT), the use of Interactive Didactic Applications (IDA) and Information and Communication Technology (ICT) into their teaching methodology.

- The use of Interactive Didactic Applications (IDA) in Computer Assisted Teaching (CAT) has reduced the time necessary for theoretical presentations, improving the visualization of models, problems and possible solutions, thereby increasing the interest and understanding of students.

- The IDA has been improved by the incorporation of the teaching of movement, through the 
animations and simulations generated by the CAD packages.

- This paper shows the increasing importance given to innovation in teaching as a vehicle for the improvement in teaching quality, with multimedia resources given a preferred place in the analyses proposed by Universities.

- This methodology allows the presentation of content with complex representation, which needs abilities of visualization and spatial comprehension.

- With slight variations, this type of material can be adapted for use in distance learning and to be a part of virtual libraries.

- The research carried out to find the most efficient was of presenting the concepts dealt with in the field of design has been successful, and this application may become a reference for engineering studies.

- The assessment performed shows that the application has a user-friendly interface, is intuitive and has a quick and efficient conceptual response. This implies a high degree of innovation, as there is no other application on the market with these characteristics.

- The evolution of hardware and of the video compression systems used allows the application to be compatible with all Windows-based systems. In addition, its small size (less than 1 GB) means that it is easily transferable.

- Future courses of action are to implement into this application control parameters to interact with the user, making it possible for example to introduce data in order to personalize the learning process, especially in the field of the analysis of mechanical elements and the design of mechanisms.

- This article presents the IDA in the field of the standardization of Technical Drawing. We are currently working to apply this methodology to other branches of science. 


\section{REFERENCES}

[1] M.F. Iskander, Benefits of virtual teaching, Comput Appl Eng Educ, 5 (1997), 1-2.

[2] E.I. Konukseven, Web-Based Education: Teaching the "Computer Aided Engineering Drawing" Course With Web, Applications of Information and Communication Technologies in Education and Training, (2004), 220-224.

[3] D.G. Ullman, S. Wood and D. Craig, The Importance of Drawing in the Mechanical Design Process, Comput \& Graph, 14 (1990), 263-274.

[4] Y.M. Bao, G.Z. Chai and x.f. Jiang, Engineering Graphics Education Reform Aiming at Cultivation of Innovative Thinking, Procedings of the International Conference on Mechanical Engineering and Mechanics 2007, Vols 1 and 2, (2007), 2186-2189.

[5] S.J. Wilson and J. Thornton, Authorware 6: Inside Macromedia, Onword Press Thomsom Learning, Australia, 2002.

[6] R. Rubio, J. Suárez, R. Gallego, S. Martín and M.S. Pérez, Animación multimedia interactiva con Macromedia Flash en la enseñanza de Expresión Gráfica, XVIII Congreso Internacional de Ingeniería Gráfica (CD), (2005), Sevilla (Spain).

[7] M. Vezzani, Mechanical Drawing training by multimedia means, XIII ADM-XV INGEGRAF Congreso Internacional de Ingeniería Gráfica (CD), (2003), Naples (Italy).

[8] E. Gutiérrez, R. Mármol, R. Baena and S. Fernández, Tutorial de dibujo mecánico y expresión gráfica en la Ingeniería, XIII INGEGRAF Congreso Internacional de Ingeniería Gráfica (CD), (2001), Badajoz (Spain).

[9] A. Carretero, M.L. Martínez, J. Félez, J.M. Cabanellas, J. Maroto and R. Álvarez, Enseñanza de Ingeniería Gráfica asistida por Internet, XI INGEGRAF Congreso Internacional de Ingeniería Gráfica (CD), (1999), Pamplona-Logroño (Spain).

[10] P.Company, M. Contero, A. Piquer, N. Aleixos, J. Conesa and F. Naya, Educational software for teaching drawing-based conceptual design skills, Comput Appl Eng Educ, 12 (2005), 257-268.

[11] P.I.A Peñin, M.R.P. Morales, D.R.R. Garcia, R.P.G. and J.S. Quiros, Multimedia-integrated 
application for computer-assisted teaching of technical drawing (Aimec-Dt), Comput Appl Eng Educ, 12 (2004), 136-144.

[12] S.C. Ou, W.T. Sung, S.J. Hsiao and K.C. Fan, Interactive web-based training tool for CAD in a virtual environment, Comput Appl Eng Educ, 10 (2003), 182-193.

[13] F. Naya, M. Contero and N. Aleixos, The Mobile Drawing Assistant, Int J Eng Educ, 23 (2007), 460 467.

[14] P.Company, M. Contero, F. Naya, P. Company and J.L. Saorin, Learning Support Tools for Developing Spatial Abilities in Engineering Design, Int J Eng Educ, 22 (2006), 470-477.

[15] B.R. Barbero, J.P. Vara, E.G. Mate and J.R. Calvo, Effectiveness of a Hypermedia Tool in the Innovative Teaching of Pneumatic Engineering Design Drawing, Comput Appl Eng Educ, 15 (2008), 289 307.

[16] B.B. Ramos, V.J. Pelaez, M.E. Garcia and C.J. Ruiz, Design, Navigation, and Structure of a Hypermedia Application for the Teaching-Learning of Pneumatic Engineering Design Drawing, Comput Appl Eng Educ, 14 (2007), 248-259. 